\title{
The Chronic Prostatitis Syndromes
}

\author{
RN Thin \\ OBE, MD, FRCPE, FRCP \\ Senior Physician
}

Department of Genitourinary Medicine, Guys and St Thomas' Hospital Trust, St Thomas' Hospital, London SE1 7EH.

SUMMARY: Three chronic prostatitis syndromes are recognised, chronic bacterial prostatitis (CBP), chronic $\frac{\overline{\bar{N}}}{\overline{5}}$ nonbacterial prostatitis (CNBP), and prostatodynia. All may occur in men of military age, and may tax the patience $\widehat{\otimes}$ of medical officers and patients whose capacity for full duty will be impaired. Diagnosis depends on identifying micro-organisms in CBP and white cells in CNBP in prostatic secretion (EPS) expressed by prostatic massage. In ${ }^{\infty}$ prostatodynia there are clinical features of prostatitis but no evidence of inflammation. Prostatic massage should be $\vec{\circ}$ preceded by trans-rectal ultrasound which may show prostatitis and other pathology, and has simplified the $\overrightarrow{\vec{\omega}}$ investigation of these syndromes. Management includes a high fluid intake, regular bowels with a soft stool, regular $\stackrel{\omega}{\omega}$ prostatic drainage by ejaculation and limited alcohol intake. Antimicrobials are indicated for CBP and probably for CNBP, and need to be continued for at least three months in many cases. Other measures for treating CNBP are less 3 well established. Prostatodynia is an ill defined syndrome which requires careful evaluation and patients may need psychiatric therapy.

\section{Introduction}

The chronic prostatitis syndromes are frequently regarded as ill defined, ill understood, difficult to diagnose, and difficult and tiresome to manage from the viewpoint of medical officer and patient (1). Over the last few years some of these difficulties have been clarified though problems remain. As these syndromes affect young men they will be found among servicemen and are worth reviewing.

\section{Anatomy and pathology}

The prostate is a tuboalveolar gland with a fibromuscular stroma and four zones within a fibrous capsule. In young men the peripheral zone is the largest and with the central zone comprises most of the volume of the gland; between them is a narrow transitional zone and there is a thin periurethral zone. The transitional zone is the site of benign hypertrophy in older men, while inflammation and cancer develop in the peripheral zone (2). Infection in the peripheral zone may be related to the right angle at which the ducts enter the urethra compared to the oblique angle of entry of the ducts draining the central zone (1). Simple histological examination of a cross section of the prostate shows inflammation to be multifocal (1).

\section{Classification of the prostatitis syndromes}

Chronic prostatitis refers to syndromes where the symptoms are subacute and persistent, compared to the dramatic features of acute prostatitis which is rare in western societies. Three common syndromes of chronic prostatitis have been described; chronic bacterial prostatitis (CBP), chronic non-bacterial prostatitis (CNBP), and prostatodynia. CBP is diagnosed when a urinary tract pathogen is isolated as described below, CNBP is diagnosed when there are excess polymorphonuclear leucocytes (PMNL) without an organism, and prostatodynia is the term used when there are symptoms of prostatitis without evidence of inflammation (1).

\section{Aetiology}

Neisseria gonorrhoeae is now rarely isolated from cas of chronic prostatitis in developed countries, but in the past was reported in prostatic abscesses $(3,4)$. Chlamydia trachomatis is not established as a cause though sorge believe it to be important $(5,6,7)$, and Ureaplas ${ }^{2}$. urealyticum has also been implicated (8). Trichomon vaginalis causes a few cases (9). Non specific urethritis may have a role in some men, but others have multiple attacks without developing prostatitis (10).

In CBP, Escherchia coli is the most commonly isolated $\stackrel{\mathbb{Q}}{\varrho}$ bacterium, though other urinary pathogens also occur $\overrightarrow{\hat{O}}$ $(11,12,13)$. There is rarely a focus of infection in the upper 3 renal tract; more commonly the prostate is the source for recurrent bacteruria (13). Prostatic calculi have been? implicated as foci of infection but calculi are common 3 from middle age onwards. A recent study identified bacterial persistence in polysaccharide coated microcolonies within prostatic tissue; some of these $\overrightarrow{\widetilde{\sigma}}$ patients had negative results to EPS cultures (14).

Though by definition no pathogens are isolated in CNBP, the inflammatory process may block the ducts 3 draining the foci preventing organisms reaching the EPS. The surrounding inflammatory exudate may drain down nearby patent ducts producing excess PMNL in the EPS without any organisms (15). Intraprostatic reflux of urine has also been suggested following the identification of $\frac{D}{O}$ urinary constituents in prostatic calculi, and direct reflux of carbon particles into the prostatic ducts has been $N$ demonstrated in humans (16).

Prostatodynia may be related to emotional disturbance, $N$ psychiatric conditions especially depression, tension myalgia in the pelvic floor muscles, functional voiding 
problems, bladder neck dyssynergia, or possibly other conditions including prostatitis itself. Pain from prostatitis or other conditions innervated by S2, 3 and 4 may also lead to tension myalgia in the pelvic floor muscles causing or exacerbating pain $(17,18,19,20)$.

\section{Prevalence}

The prevalence of these syndromes is unclear. In 1970 at the venereal disease clinic in the British Military Hospital Singapore, $36.8 \%$ of 95 men who had been treated three months previously for urethral gonorrhoea and $13.6 \%$ of 66 men treated for non-gonococcal urethritis were diagnosed as having prostatitis. At the Royal Herbert Hospital, Woolwich, $16.7 \%$ of 36 men treated for gonococcal urethritis and $35.4 \%$ of 48 men treated for nongonococcal urethritis were diagnosed as having prostatitis (21). In the UK and Holland civilian general practitioners diagnose 1-10 patients per year $(22,23)$. In Germany at a urological department with an interest in these syndromes, $5-10 \%$ were CBP, $60-65 \%$ CNBP, and $30 \%$ prostatodynia (8). In the UK at a tertiary referral clinic for chronic prostatitis, 30\% were CBP, 40\% CNBP and 30\% prostatodynia; ages ranged from 20 to 56 years and were similar in the three syndromes (10).

\section{Clinical features}

Symptoms are similar in all three syndromes and are listed in Table 1. Digital examination of the prostate is frequently unhelpful. Tenderness localised definitely to one area of the prostate is very suggestive of prostatitis, tenderness referred to the urethra or penile tip is suggestive, but generalised tenderness is difficult to interpret. Tenderness contraindicates prostatic massage

Table 1

Symptoms of the chronic prostatitis syndromes

\begin{tabular}{ll}
\hline Pain/discomfort & Perineal \\
& Penile tip or urethral \\
& Within scrotum \\
& Inguinal \\
& Suprapubic or retropubic \\
& lliac fossa and inguinal \\
& Rectal \\
& General genital \\
& Low back \\
& Burning \\
Urinary symptoms & Frequency \\
& Urgency \\
& Urethral discharge \\
& Haematuria \\
\hline
\end{tabular}

\section{$(1,18)$. Diagnosis rests on investigations $(1,18)$.}

\section{Investigations}

Established methods comprise cytological and cultural examination of prostatic secretion (EPS) and of urine passed before and afterwards (24). If there is any
Table 2

Prostatic investigations - the Stamey technique

\section{Procedure}

1. Retract prepuce if present and clean end of penis with sterile saline or water

2. Collect first $5-10 \mathrm{ml}$ urine - Voided bladder urine 1 (VB1)

3. Pass approximately $200 \mathrm{ml}$ into toilet

4. Collect next $5-10 \mathrm{ml}$ urine - mid stream urine or Voided bladder urine 2 (VB2)

4. Prostatic massage and collect expressed prostatic secretion (EPS) into sterile container

5. Collect next 5-10 ml - Voided bladder urine 3 (VB3)

\section{Table 3}

Interpretation of prostatic investigations

\begin{tabular}{|c|c|c|c|c|}
\hline Interpretation & VB1 & VB2 & EPS & VB3 \\
\hline Urethritis & Cells $^{1}+\mathrm{Orgs}^{2}$ & $2-$ & - & - \\
\hline Bacteruria & \pm Orgs & Orgs & - & Orgs \\
\hline CBP & - & - & Orgs+Cells & Orgstcells \\
\hline CNBP & - & - & Cells & Cells \\
\hline Prostatodynia & - & - & - & - \\
\hline
\end{tabular}

suggestion of urethritis the patient should be referred to genitourinary medicine clinic before prostatic massage.

The details of prostatic investigations and thex interpretation are summarised in Tables 2 and 3. Thi method is often referred to as the Stamey technique after the senior author who first described it (24). Patients should be advised to hold their urine for two hours and avoid ejaculation for two days before investigation. No prostate penetrating antimicrobial (see below) should be taken for at least a week before investigation. Samples should be examined as soon as possible; this needs close collaboration with the laboratory. Simple microscopic estimations of white cells can be done in the clinic and counts can also be done on the spot using a Fuchs Rosenthal counting chamber (18). Ideally quantitative aerobic and anaerobic microbiological cultures should be done (25).

Where possible, before undertaking prostatic investigations a transrectal ultrasound scan (TRUS) of the prostate should be undertaken. This may show changes that are typical though not diagnostic of prostatitis. TRUS may also indicate conditions which may be confused with or complicate prostatitis including prostatic cysts, abscesses and calculi, disease of the seminal vesicles, bladder neck dysfunction, benign prostatic hypertrophy and carcinoma. TRUS may also suggest the rare granulomatous, eosinophilic and tuberculous forms of $N$ prostatitis. A normal scan may be found with an abnormal EPS. A major role for TRUS is to guide a needle for aspiration or biopsy, though the multifocal nature of 
Table 4

Additional investigations

\author{
Urine cytology \\ EMUs for MTB \\ Serum prostate specific antigen \\ Renal tract USS or IVU \\ Flow rate \\ Cystourethroscopy \\ Urodynamics
}

prostatitis does not usually lend itself to needle aspiration unless complicated by a cyst or abscess (10).

\section{Diagnosis}

The diagnosis of CBP is based on finding a pure growth of a urinary pathogen in the EPS and post prostatic massage urine or voided bladder urine 3 (VB3) in the absence of simple bacteruria. In CNBP a white cell count of $1000 \mathrm{PMNL} / \mathrm{cu} \mathrm{mm}$ in the EPS is regarded as diagnostic; if simple microscopy of the EPS is undertaken at least $10 \mathrm{PMNL} / \mathrm{X} 40$ microscope field are required. Clumping of PMNL also indicates prostatitis. If EPS is not obtained, increased PMNL in the VB3 is associated with prostatitis. A raised EPS $\mathrm{pH}(>8.0)$ is corroborative, but prostatitis may be present with a lower $\mathrm{pH}$. Prostatodynia is diagnosed when there are clinical features suggesting prostatitis but no pathogen or excess PMNL can be demonstrated (10).

\section{Differential diagnosis}

The chronic prostatitis syndromes may mimic or coexist with a variety of conditions within and outwith the urinary tract. Carcinoma of the prostate and elsewhere in the lower genital tract is most important and is usually found in older men. Other prostatic pathology including cysts, abscesses, calculi and benign prostatic hypertrophy will be shown by TRUS which may also show disease of the seminal vesicles. Bladder diverticula will be recognised on upper renal tract imaging. Warts or extra folds of mucosa in the upper urethra may disturb urine flow and cause prostatitis; these are extremely rare.

These conditions will be excluded by undertaking the investigations outlined for the diagnosis of prostatitis and those listed in Table 4. Urine cytology, serum prostate specific antigen (PSA) and EMUs should be requested for all patients. PSA may be elevated in prostatitis and carcinoma. Any person with obstructive symptoms should have a flow rate. Renal tract imaging is less important for younger men with the advent of TRUS. However men over 45 years, any man with haematuria or any feature suggesting carcinoma should have renal tract imaging and referral for endoscopy before prostatic massage or treatment for prostatitis.

Conditions outside the renal tract must also be considered. Diverticulitis can cause irritative voiding symptoms and pain suggesting prostatitis but usually presents in older men. Inguinal region pain may be due to a hernia or ligament disease, while pain may also be referred from the spine. Genital herpes may also cause confusing pain before lesions appear.

\section{Management}

In all the prostatitis syndromes general measures? including explanation, reassurance, counselling and $\vec{F}$ psychological support are important. In addition a high $\stackrel{\text { ? }}{?}$ fluid intake, such as 3 litres daily, regular bowel habit with? a soft stool, and regular prostatic drainage by ejaculation $\frac{\bar{\sigma}}{\bar{\omega}}$ are all beneficial $(15,26)$. Possibly regular overall habits $\frac{\widetilde{\sigma}}{\widetilde{D}}$ help. Patients should not be set unrealistic targets which lead to anxiety. The natural history of chronic prostatitis ises gradual improvement with intermittent exacerbation of $\vec{\circ}$ symptoms; this must be explained. Sometimes theseexacerbations have an explanation such as reduced fluide intake; others are inexplicable.

Antimicrobials which theoretically penetrate well into the prostate should be lipid soluble, low protein binding, and with an appropriate dissociation constant (high $\mathrm{pKa}) \overrightarrow{\mathrm{f}}$ (27). These include trimethoprim, minocycline, doxycycline, erythromycin, azithromycin, and thec quinolones of which ciprofloxacin has been the mosto studied $(27,28)$. Experience suggests that full doses areo required for three or more months. Progress can monitored objectively by repeating the EPS examination. In CBP a pathogen is identified and antimicrobs sensitivities obtained. Ciprofloxacin $250-500 \mathrm{mg}$ 하윰 trimethoprim $200 \mathrm{mg}$ twice daily are usually effecti这 $(27,29)$.

In CNBP there is a rationale for giving antimicrobiक्⿹勹巳欠. following the hypothesis of blocked ducts. Antimicrobi may be selected on the basis of the history; if this suggegs bacteruria then a quinolone or trimethoprim may $\vec{b}=\frac{\bar{C}}{\bar{c}}$ chosen; if there has been recurrent urethritis theng doxycycline, minocycline, erythromycin or azithromycinō may be given One controlled study of erythromycin suggested benefit compared to placebo (30). In anothero non-random study trimethoprim and minocycline gave greater reduction in EPS PMNL counts than co trimoxazole or diazepam (31). In two small randomised double blind trials of minocycline versus diazepam and doxycycline versus placebo, the antimicrobials gave bettero results $(32,33)$.

Other suggestions include anti-inflammatories though little evidence has been found to support their use and personal clinical experience has been disappointingo $(15,34)$. Pollen extract has been described as beneficial; ite. may be anti-inflammatory through prostaglandin synthesiso inhibition and by anti-adrenergic activity $(35,36)$. Severaß reports have described improvement following transrecta! or transurethral microwave hyperthermia $(37,38)$.

Acute exacerbations of symptoms may respond to short course of propantheline, or prednisolone though onlyñ one reference has been traced for this (34).

In prostatodynia, emotional and psychiatric conditions may need specialist care (19). Tension myalgia improves when the patient relaxes; for example some patients gee 
relief from pain when they relax in the evening or when on holiday. Alcohol should be avoided as some patients report exacerbation of pain almost as soon as they start an alcoholic drink; reasons for this are obscure. Large amounts of alcohol are contraindicated as they may increase voiding problems and cause subsequent dehydration. Functional voiding problems and bladder neck dyssnyergia may be recognised during TRUS and managed with alpha blockers which relax smooth muscle in the bladder neck (39). Although this group of drugs is frequently recommended personal experience has been disappointing and patients with bladder neck dyssynergia may need referral to a urologist for incision of the sphincter.

\section{Comment}

The classification repeated here has been accepted for some years; the concept of prostatodynia is somewhat vague but appears to be retained for the clinical similarity with CBP and CNBP (1). If prostatodynia is thought to be the diagnosis, organic causes for the symptoms must be considered before settling for a psychological aetiology.

TRUS has greatly simplified investigation of these syndromes and many patients who would previously have been subjected to IVU and endoscopy are now spared these invasive investigations. Prostatic massage to obtain EPS is a tedious procedure and it has been suggested that a mid-stream urine before prostatic massage or voided bladder urine 2 (VB2) and VB3 samples may be sufficient; without EPS CBP may be missed (10). If EPS cannot be obtained then VB3 should be sent for investigation, but repeat prostatic massage should be considered.

Unlike some published data, clinical experience indicates that prolonged treatment is required for most patients. Intra-prostatic injection of antimicrobials has been described but reports of response have been variable (40). The logic of introducing high concentrations of antimicrobials into one area of multifocal inflammation are unclear; at least the process of needling the prostate can be done more safely with TRUS control. More research is clearly needed into aetiology and management. Until new answers are found these chronic syndromes will tax the patience of medical officers and their patients whose capacity for full duty will be impaired.

\section{REFERENCES}

1. THIN RN. The diagnosis of prostatitis; a review. Genitourin Med 1991; 67: 279-283.

2. MCNEAL JE. Anatomy and embryology. In: Fitzpatrick JM, Krane RJ, eds. The prostate. Edinburgh: Churchill Livingstone, 1989; 3-10.

3. SARGENT JC, IRWIN R. Prostatic abscess: clinical study of 42 cases. Am J Surg 1931; 11: 334-337.

4. PAL MG, BHAT HS. Prostatic abscess. J Urol 1972; 108: 599-600.

5. Doble A, Taylor Robinson D. The diagnosis, aetiology, and pathogenesis of chronic abacterial prostatitis. In: Weidner W, Madsen PO, Schiefer HG, eds. Prostatitis:etiopathology, diagnosis and therapy. Berlin: Springer Verlag, 1994; 215-228.

6. Koroku M, Kumanto Y, Hirose T. A study on the role of Chlamydia trachomatis in chronic prostatitis analysis of anti-Chlamydia trachomatis specific $\lg \mathrm{A}$ in expressed prostatic secretion by western blotting method. J Jap Ass Infect Dis 1995; 69: 426-437.

7. MARUTA N. Study of Chlamydia trachomatis in chronic prostatitis. Acta Urologica Japonica 1992: 38: 297304.

8. BrunNer H, WeidNer W, SCHIEFFer HG. Studies on the role of Ureaplasma urealyticum and Mycoplasma hominis in prostatitis. J Infect Dis 1983; 147: 807-13.

9. KRIEGER JN. Trichomoniasis in men: old issues and new data. Sex Transm Dis 1995; 22: 83-96.

10. THIN RN. Chronic prostatitis; overview and update. Int J STD AIDS 1997; 8: In press.

11. LeIGH DA. Prostatitis - an increasing clinical problem for diagnosis and management. $J$ Antimicrob Chemother 1993, 32 (Suppl A): 1-9.

12. DoBle A. Chronic prostatitis. Br J Urol 1994; 74: 537541.

13. Meares EM Jr. Prostatitis and related disorders. In: Walsh PC, Retik AB, Stamey TA, Vaughan ED, Jr, eds. Campbell's Urology, (6th edn). New York: Saunders刀 1992; 807-822.

14. NiCKel JC, COSTERTON JW. Bacterial localisation i antibiotic-refractory chronic bacterial prostatitis Prostate 1993; 23: 107-14.

15. THIN RNT. Therapy of non-bacterial prostatitis. In Weidner W, Madsen PO, Schiefer HG, eds. Prostatitio.$v$ etiopathology, diagnosis and therapy. Berlin: Springes Verlag, 1994; 254-259.

16. Kirby RS, Lowe D, Bultitude M, Shuttleworth KED. Intraprostatic urinary reflux: an aetiological factor in abacterial prostatitis. $\mathrm{Br} J$ Urol 1982; 54: 729731.

17. Weidner W, Madsen PO, Schiterer HG. Preface. In: WeIDNER W, MADSEN PO, SchIEFER HG, eds. Prostatitis; etiopathology, diagnosis and therapy. Berlin: Springer-Verlag IX.

18. ThIN RN, SIMmons PD. Chronic bacterial and nonbacterial prostatitis. Br J Urol 1983; 55: 513-518.

19. Woodhouse CRJ, RugG AJ. Chronic perineal pain. $\mathrm{Br}$ J Hosp Med 1984: 302-304.

20. EGAN KJ, KRIEGER JN. Psychological problems in chronic prostatitis patients with pain. Clin J Pain 1994; 10: $218-26$.

21. THIN RNT. Prostatitis after urethritis in Singapore. $B r, J$ Vener Dis 1974, 50: 370-372.

22. Curtis S, Edwards A, LuZZI GA. Prostatitis in the community - results of a general practitioner survey (Abstract not numbered). Medical Society for the Study of Venereal Diseases, Spring Meeting, Vienna, 1995.

23. De la Rosette JJMCH, Hubregste MR, Karthaus HFM, DEBRUYNe FMJ. Results of a questionnaire among Dutch urologists and general practitioners concerning diagnostics and treatment of patients with 
prostatitis syndromes. Eur Urol 1992; 22: 14-19.

24. MEAREs EM, StAMEY TA. Bacteriologic localisation patterns in bacterial prostatitis and urethritis. Invest Urol 1968; 5: 492-518.

25. THIN RNT, Simmons PD, WoOd RC. Difficulties in diagnosing prostatitis. Results of repeated samples of expressed prostatic secretion (EPS). In: Weidner W, Brunner $\mathrm{H}$, Krause W, Rothauge CF, eds. Therapy of prostatitis. Munchen: Zuckschwerdt Verlag, 1986; 145-148.

26. EVANS DTP. Treatment of chronic abacterial prostatitis: a review. Int $J$ STD AIDS 1994; 5: 157 164.

27. Madsen PO, Drescher P, Gasser TC. Basis for antibacterial treatment of prostatitis: experimental and clinical pharmacokinetic studies and models. In: Weidner W, Madsen PO, Schiefer HG, eds. Prostatitis, etiopathology, diagnosis and therapy. Berlin: Springer Verlag, 1994; 110-122.

28. Fouldos G, Madsen P, Cox C, Shepard R, Johnson R. Concentration of azithromycin in human prostatic tissue. Eur J Clin Microbiol Infect Dis 1991; 10: 868871.

29. Weidner W, Schiefer HG, Dalhoff A. Treatment of chronic bacterial prostatitis with ciprofloxacin; results of a one year follow up study. Am J Med 1987; 82 (Suppl 4A): 280-283.

30. HoOton TM, Wong ES, BARNES RC, RoBerTS PL, STAMM WE. Erythromycin for persistent or recurrent nongonococcal urethritis. A randomised placebo controlled trial. Ann Intern Med 1990; 113: 21-26.

31. THIN RN, Simmons PD. Review of results of four regimens for treatment of chronic non-bacterial prostatitis. Br J Urol 1983; 55: 519-521.
32. SIMMONS PD, THIN RN. Minocycline in chronic abacterial prostatitis: a double blind prospective trial. BrJ Urol 1985; 57: 43-45.

33. Simmons PD, ThIN RNT. Doxycycline in chronic abacterial prostatitis (Abstract - not numbered). Medical Society for the Study of Venereal Diseases. Spring Meeting. Bordeaux: 1989.

34. Meares EM. Prostatitis: diagnosis and treatment. Drugs 1978; 15: 478-482.

35. BuCK AC, REEs RWM, EBELING L. Treatment of chronic prostatitis and prostatodynia with pollen extract. Br J Urol 1989; 64: 496-499.

36. RugendoRfF EW, WEIDNER W, EBELING L, BuCK AC. के Results of treatment with pollen extract (Cernilton $\left.{ }^{\mathrm{R}} \mathrm{N}\right) \overrightarrow{0}$ in chronic prostatitis and prostatodynia. $\mathrm{Br} J \mathrm{Urol}$ 1993; 71: 433-438.

37. Montorsi F, Guazzoni G, Bergamaschi F, et al. Is there a role for transrectal microwave hyperthermia of the prostate in the treatment of abacterial prostatitis and prostatodynia, Prostate 1993; 22: 139-146.

38. SHAH TK, WATSON GM, BARNES DG. Microwave hyperthermia in the treatment of chronic abacterial 4 prostatitis and prostatodynia: results of a double blind 8 placebo controlled trial (abstract). J Urol 1993; 149 (Suppl): 405A.

39. NEAL DA, MOON TD. Use of terazosin prostatodynia and validation of a symptom scor questionnaire. Urology 1994; 43: 460-465.

40. BAERT L, DE RIDDER D. In loco antibiotics in chronie bacterial prostatitis. In: Weidner W, Madsen PO Schiefer HG, eds. Prostatitis; etiopathology, diagnose.$v$ and therapy. Berlin: Springer-Verlag, 1994; 191-196 